\title{
Swallow Syncope: A Case Report and Review of the Literature
}

\author{
Subhashis Mitra, MD; Tiffany Ludka, MD; Shereif H. Rezkalla, MD; \\ Param P. Sharma, MD and Jiangming Luo, MD, PhD
}

\begin{abstract}
Swallow or deglutition syncope is a relatively rare syndrome. It is a vagally mediated syncope induced by swallowing. Swallow syncope may occur in all age groups and, when diagnosed, is treatable. A woman, aged 60 years, presented with an episode of a syncopal attack associated with swallowing a sandwich. She had a 6-month history of recurrent episodes of lightheadedness while eating solid foods. Telemetry monitoring demonstrated several episodes of severe bradycardia and complete atrioventricular block with up to a 7.0 second pause associated with meals. Computed tomography of the head and neck revealed no significant findings, and barium esophagram was normal. Echocardiogram was within normal limits. Her symptoms resolved after permanent pacemaker placement. Herein, we review the diagnosis, mechanism, and management of swallow syncope.
\end{abstract}

Keywords: Syncope, Swallow, Computed tomography, Bradycardia, Atrioventricular block, Pacemaker, Diagnosis

Corresponding Author:

Jiangming Luo, MD, PhD

Marshfield Clinic

Department of Hospital Medicine

1000 N Oak Ave

Marshfield WI 54449

Tel: (7I5) 387-5537

Email: luo.jiangming@marshfielddlinic.org

Received: September 27, 2010

Revised: November 17,2010

Accepted: November 18, 2010

doi: $10.3121 / \mathrm{cmr} .2010 .969$
$\mathrm{S}$ llow syncope is a relatively rare cause of syncope that belongs to the neurally-mediated reflex syncopal syndromes. It occurs due to a vagal reflex during deglutition causing inhibition of the cardiac conduction system. Since the first reported case of swallow syncope in 1773 by Spens, ${ }^{1}$ there have been only about 80 case reports of swallow syncope in the literature to date. In most cases there was an underlying abnormality in the esophageal or cardiac conduction system. However, there have been reported cases without any esophageal or cardiac abnormality. In this article, we report a case of swallow syncope and review the literature.

\section{Case report}

A woman, aged 60 years, was admitted to the hospital with a history of recurrent episodes of lightheadedness and one episode of syncope. She reported having several episodes of lightheadedness while eating solid food for the last six months. During these episodes she would usually stop eating, and the feeling of lightheadedness would spontaneously subside. She was admitted for further evaluation after she lost consciousness while eating a peanut butter sandwich. Her past medical history was significant for hypertension and hyperlipidemia. She had been on treatment with atenolol since 2004 and was taking $100 \mathrm{mg}$ once daily since 2005. Her family history was unremarkable for any arrhythmias or syncope. On admission, her heart rate was 54 beats per minute (bpm) and blood pressure was $160 / 94 \mathrm{mmHg}$ with no evidence of orthostatic hypotension. The remainder of the physical examination, including a comprehensive neurological examination, was normal. Hematological and biochemical tests were normal. A 


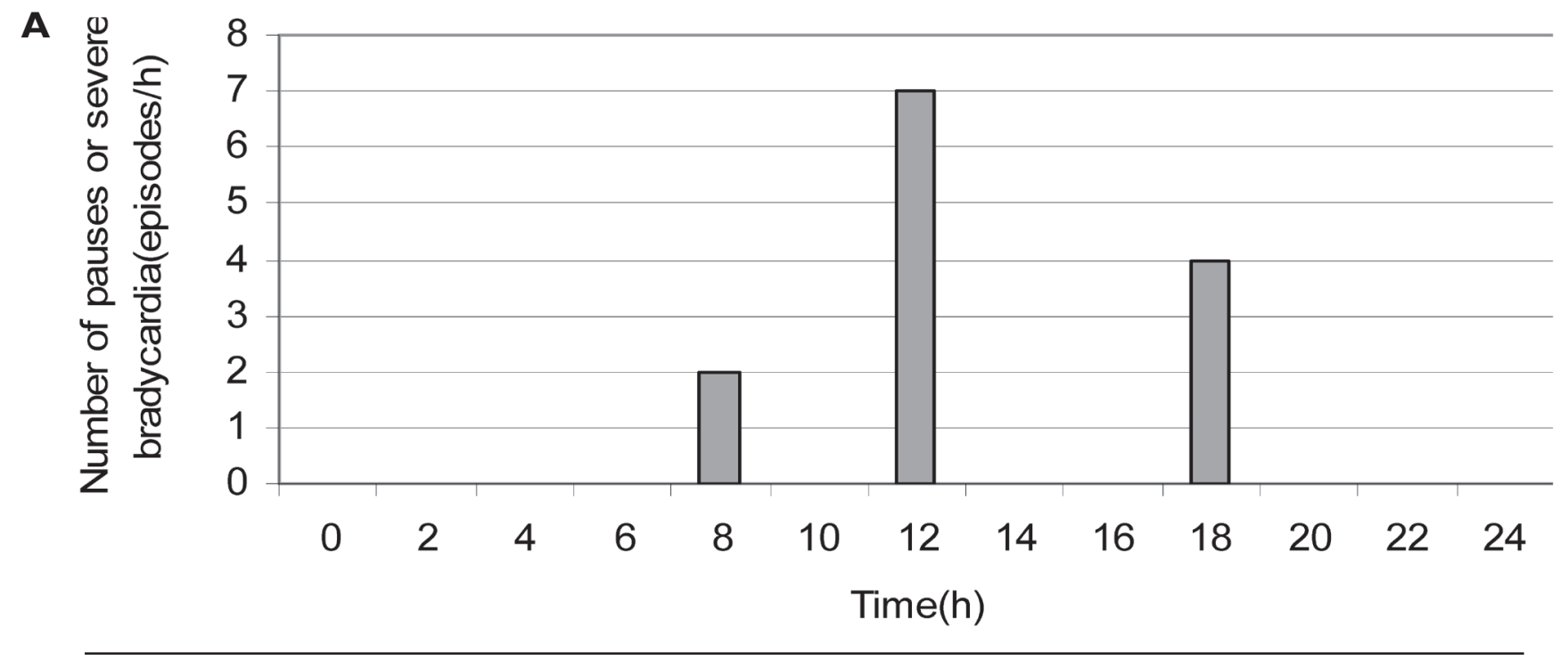

B

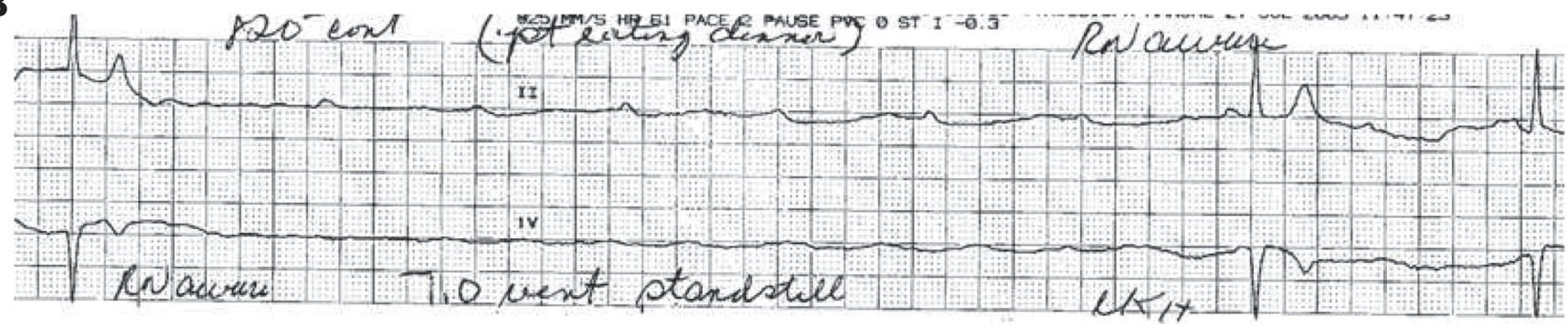

Figure 1. Telemetry and representative electrocardiogram of cardiac pause. (A)The number of severe bradycardia of less than 35 beats per minute or cardiac pauses of more than 2.0 seconds is shown in the trend-gram. The episodes occurred only during meals, especially lunch. (B) A telemetry strip shows ventricular asystole of 7.0 seconds that occurred during a meal.

12-lead electrocardiogram (ECG) showed sinus bradycardia with a rate of $54 \mathrm{bpm}$ and first-degree atrioventricular (AV) block with a PR interval of 224 milliseconds. Carotid massage did not produce any symptoms or conduction abnormalities. A chest radiograph did not reveal any cardiopulmonary abnormality and an echocardiogram was within normal limits. Her atenolol was discontinued after admission. Telemetry monitoring demonstrated multiple episodes of severe sinus bradycardia (less than $35 \mathrm{bpm}$ ) and complete AV block with pauses up to 7.0 seconds during meal times (figure 1A). A representative telemetry strip showing a 7.0 second pause during the meal time is shown in figure 1B. Computed tomography of the head, cervical spine, and neck revealed no significant findings, and a barium esophagram was normal. Two days after discontinuing atenolol the patient underwent another swallow test to see if this reproduced her symptoms. She was challenged with tap water, cold water, hot tea, cold soda, pudding, a bagel, and an English muffin in that order. Five to ten seconds after taking the muffin, four episodes of second-degree type $2 \mathrm{AV}$ block were detected on the rhythm strip. Liquids (hot or cold) and soft food did not cause any problem. She underwent implantation of a Saint Jude model \#5826, dual chamber permanent pacemaker before being discharged. The patient remains asymptomatic after six months.

\section{Discussion}

Swallow syncope is a relatively rare syndrome and belongs to the "reflectional syncope" syndromes. Omi et $\mathrm{al}^{2}$ reviewed 63 reported cases of swallow syncope in children and adults from the English-language literature between 1793 and 2005. Since then, another 17 cases have been reported in the English literature (table 1). This syndrome is more common in males, and most patients have been adults, but some cases were also noted in young children. ${ }^{2}$ Swallow syncope has been known to occur in patients with organic or functional disorders of the esophagus. These disorders include esophageal spasm, esophageal stricture, achalasia, esophageal diverticula, esophageal cancer, and hiatal hernia. ${ }^{2}$ Swallow syncope may also occur in the absence of esophageal diseases and has been observed in the setting of cardiac diseases like acute myocardial infarction, rheumatic carditis, and with digoxin use. $^{2}$ Some reported cases were associated with ascending aortic aneurysm, ${ }^{3}$ thoracic surgery, advanced lung cancer, and transient hypoxia. ${ }^{2}$ However, in a significant number of cases, no underlying disease could be found. ${ }^{2}$ Table 2 shows the distribution of underlying disease in the previously reported 80 cases of swallow syncope.

The pathophysiology of swallow syncope is not completely understood, and several different mechanisms may exist. Vagal reflex plays a major role, as pretreatment with atropine 
Table 1. Swallow syncope cases published since report by Omi et al. ${ }^{2}$

\begin{tabular}{|c|c|c|c|c|c|c|c|c|}
\hline & Author & $\begin{array}{l}\text { Age/ } \\
\text { Gender }\end{array}$ & $\begin{array}{l}\text { Underlying } \\
\text { disease }\end{array}$ & Type of food & Type of arrhythmia & Treatment & Effective & F/U \\
\hline 1 & Turan $2005^{9}$ & 48/M & Achalasia & Solid food (bread) & Sinus bradycardia & $\begin{array}{l}\text { Pacemaker } \\
\text { implantation, } \\
\text { balloon dilatation } \\
\text { of achalasia }\end{array}$ & $\mathrm{Y}$ & $18 \mathrm{mo}$ \\
\hline 2 & Gawrieh $2005^{10}$ & $63 / \mathrm{M}$ & Schatzki ring & Dry solid food & AV block, Asystole & $\begin{array}{l}\text { Pacemaker } \\
\text { implantation }\end{array}$ & $\mathrm{Y}$ & $26 \mathrm{mo}$ \\
\hline 3 & Gawrieh $2005^{10}$ & $63 / \mathrm{M}$ & $\begin{array}{l}\text { Hiatal hernia } \\
\text { with Schatzki } \\
\text { ring, CAD }\end{array}$ & $\begin{array}{l}\text { Both solid and } \\
\text { liquids }\end{array}$ & None & $\begin{array}{l}\text { Treatment refused } \\
\text { by patient }\end{array}$ & $\mathrm{N} / \mathrm{A}$ & $\mathrm{N} / \mathrm{A}$ \\
\hline 4 & Gawrieh $2005^{10}$ & $62 / F$ & $\begin{array}{l}\text { Nutcracker } \\
\text { esophagus }\end{array}$ & $\begin{array}{l}\text { Both solid and } \\
\text { liquids }\end{array}$ & $\begin{array}{l}\text { Sinus bradycardia } \\
\text { and arrest }\end{array}$ & $\begin{array}{l}\text { Pacemaker } \\
\text { implantation }\end{array}$ & $\mathrm{Y}$ & $4 \mathrm{mo}$ \\
\hline 5 & Favaretto $2008^{11}$ & $63 / \mathrm{M}$ & Hiatus hernia & $(-)$ & Sinus arrest & $\begin{array}{l}\text { Pacemaker } \\
\text { implantation }\end{array}$ & $\mathrm{Y}$ & $8 \mathrm{mo}$ \\
\hline 6 & Karamitsos $2009^{12}$ & $82 / F$ & Hiatus hernia & $(-)$ & $(-)$ & $(-)$ & $(-)$ & $(-)$ \\
\hline 7 & Bajwa $2008^{13}$ & $51 / \mathrm{M}$ & GERD & Solid food & Sinus bradycardia & $\begin{array}{l}\text { Pacemaker } \\
\text { implantation }\end{array}$ & Y & $8 w k$ \\
\hline 8 & Leitman $2010^{14}$ & $37 / \mathrm{M}$ & Megaesophagus & Large meal & $(-)$ & $\begin{array}{l}\text { Deflation of balloon } \\
\text { of gastric band }\end{array}$ & $(-)$ & $(-)$ \\
\hline 9 & Casella $2009^{15}$ & $66 / M$ & $\begin{array}{l}\text { Sick sinus } \\
\text { syndrome }\end{array}$ & Liquids & AV block & $\begin{array}{l}\text { Pacemaker } \\
\text { implantation }\end{array}$ & $\mathrm{Y}$ & $6 \mathrm{mo}$ \\
\hline & Lee $2010^{16}$ & $62 / \mathrm{M}$ & Atrial fibrillation & Cold beverages. & Ventricular asystole & $\begin{array}{l}\text { Pacemaker } \\
\text { implantation }\end{array}$ & $\mathrm{Y}$ & $(-)$ \\
\hline & Patsilinakos $2007^{3}$ & $86 / F$ & $\begin{array}{l}\text { Ascending aorta } \\
\text { aneurysm }\end{array}$ & Meals & Sinus pause & Dietary modification & $\mathrm{Y}$ & $10 \mathrm{mo}$ \\
\hline & Endean $2010^{17}$ & 61/M & $\begin{array}{l}\text { Bilateral internal } \\
\text { carotid artery } \\
\text { stenosis, carotid } \\
\text { endarterectomy }\end{array}$ & Solid food & $(-)$ & Glycopyrrolate & $\mathrm{Y}$ & $6 \mathrm{mo}$ \\
\hline & 3 Kang $2005^{4}$ & $59 / \mathrm{M}$ & Graves disease & $(-)$ & Junctional rhythm & $\begin{array}{l}\text { Behavioral } \\
\text { modification }\end{array}$ & $(-)$ & $(-)$ \\
\hline & Kang $2005^{4}$ & $59 / \mathrm{M}$ & None & Liquids/sticky food & Sinus arrest & $\begin{array}{l}\text { Pacemaker } \\
\text { implantation }\end{array}$ & $\mathrm{Y}$ & $(-)$ \\
\hline & Tuzcu $2007^{18}$ & $16 / F$ & None & Solid food & Complete AV block & $\begin{array}{l}\text { Pacemaker } \\
\text { implantation }\end{array}$ & $\mathrm{Y}$ & $12 \mathrm{mo}$ \\
\hline & Fahrner $2008^{19}$ & $75 / \mathrm{M}$ & None & $(-)$ & AV block & $\begin{array}{l}\text { Pacemaker } \\
\text { implantation }\end{array}$ & $\mathrm{Y}$ & $(-)$ \\
\hline & Boos $2008^{20}$ & $25 / F$ & None & $\begin{array}{l}\text { Solid food(sandwich) } \\
\text { and fizzy drinks }\end{array}$ & AV block & $\begin{array}{l}\text { Pacemaker } \\
\text { implantation }\end{array}$ & $Y$ & $5 \mathrm{mo}$ \\
\hline
\end{tabular}

(-), Not mentioned; N/A, Not applicable; Y, Yes; F/U, Follow-up; M, Male; F, Female; mo, month; wk, week

is effective in preventing bradycardia and syncope in a significant number of patients. The common innervation of the esophagus and heart by the vagus nerve has been postulated to play an important role in swallow syncope. Mechanoreceptors in the esophagus, which are activated by stretching, may play an important role. ${ }^{4}$ They sense distension and send signals along the esophageal plexus via the vagus nerve to the brainstem. The efferent impulses from the brainstem reach the sinoatrial (SA) node via the right vagus nerve and the AV node via the left vagus nerve. The efferent signals lead to various types of paroxysmal bradyarrhythmias and temporary reduction of cardiac output, which leads to cerebral hypoperfusion and possibly to syncope. Others have observed that swallow syncope can occur even in the absence of bradycardia, as increased afferent vagal stimulation may lead to syncope via sympathetic withdrawal, resulting in peripheral vasodilation and hypotension. ${ }^{5}$ Although other arrhythmias such as sinus bradycardia, sinoatrial block, and complete atrial and ventricular asystole have been observed, AV block has been reported most frequently.
Paroxysmal atrial fibrillation could also be associated with swallow syncope. ${ }^{6}$

The diagnosis of swallow syncope requires careful elicitation of the temporal relationship between swallowing liquids or solid foods and lightheadedness and syncope. Provocative testing with various types of liquid and solid foods should be attempted. As esophageal disorders may be associated with a majority of cases of swallow syncope, further work-up to exclude possible structural or functional esophageal pathology has been suggested. Echocardiogram and resting and ambulatory ECG should be performed to rule out any underlying cardiac pathology.

Management of swallow syncope involves withdrawal of all medications that can cause delay in cardiac conduction and inappropriate vasodepression. Avoidance of carbonated fluids or other agents associated with symptoms, as well as behavioral modification to change eating habits, may be successful in patients with infrequent episodes of syncope. ${ }^{7}$ 
Table 2. Distribution of underlying diseases in the previously reported 80 cases of swallow syncope.

\begin{tabular}{|c|c|c|c|c|}
\hline Underlying disease & Digestive disease & Cardiac disease & Other & None or unknown \\
\hline $\begin{array}{l}\text { Number of cases } \\
(\mathrm{N}=80)\end{array}$ & 31 & 12 & 6 & 31 \\
\hline Percentage of total & $38.75 \%$ & $15 \%$ & $7.5 \%$ & $38.75 \%$ \\
\hline
\end{tabular}

Various anti-cholinergic medications like atropine, scopolamine, and propantheline have been used to prevent bradyarrhythmias by blocking vagal conduction. Sympathomimetic agents like adrenaline and isoprenaline have been used to increase the ventricular rate directly; however, the results have been inconsistent and limited by side effects. ${ }^{2}$ Beta-blockers may be effective in carefully selected patients. ${ }^{8}$ In the appropriate clinical setting, correction of any underlying esophageal pathology should be attempted. Permanent pacemaker placement is usually effective in patients in whom bradyarrhythmias are the major cause of syncope.

Because swallow syncope is a rare disease, there have been no randomized controlled trials comparing the efficacy of different treatment remedies such as medications, surgery, or pacemakers. However, it is logical to treat the underlying diseases of swallow syncope if they can be found and are treatable. For example, gastroesophageal reflux disease can be treated with proton pump inhibitors, and hiatal hernia can be treated with surgery. In the large majority of swallow syncope cases there is an associated reflex bradycardia leading to cerebral hypoperfusion and syncope. Of the previously reported 80 cases of swallow syncope, 68 cases $(85 \%)$, including underlying causes such as digestive diseases as well as unknown causes, were found to have sinus arrest, sinus bradycardia, SA block, or AV block. Therefore, placement of a pacemaker represents a reasonable treatment option that allows for over-riding of the bradycardia, although it does not treat the cause of the problem. The 11 cases listed in table 1 who had pacemaker implantation, all had resolution of symptoms over a follow-up period of 2 to 26 months, ${ }^{9-20}$ indicating that pacemakers are an effective treatment. However, pacemaker implantation is not without risks that need to be balanced with the potential benefits. Approximately $4 \%$ to $5 \%$ of patients will have a complication during or following pacemaker placement, such as infection, lead dislodgment, pneumothorax, and cardiac perforations. ${ }^{21}$ There have been cases where pacemakers failed to resolve the symptoms. Armstrong et $\mathrm{al}^{22}$ reported a case of a patient with swallow syncope who had an esophageal web, moderate hiatal hernia, and spastic narrowing of the esophagus, but no bradycardia was documented. Pacemaker placement was unsuccessful in this case, and the patient died of congestive heart failure two years later. It is important that a definitive diagnosis of cardiac rhythm disturbance be established prior to insertion of a permanent cardiac pacemaker. ${ }^{22}$ In patients who do not respond to pacing therapy, volume repletion, increased salt intake, leg stockings, and avoiding ingestion of specific foods/beverages or behaviors associated with symptoms may be of value; ${ }^{22}$ however, no systematic study on this patient population has been reported. A careful search for underlying causes not involving bradycardia may be warranted. For instance, left atrial compression should be ruled out by echocardiography. ${ }^{23}$ A large hiatal hernia can cause extrinsic compression of the left atrium during meals and impede cardiac output leading to hypotension and syncope. These patients can get relief of their symptoms by surgical repair of the hernia. ${ }^{23,24}$ A pacemaker would not provide any benefit because bradycardia is not involved.

Swallow syncope, though generally considered a benign condition, can cause significant impairment of quality of life and can result in significant injury if it occurs at certain times like driving or operating heavy machinery. However, it is a treatable disease. A thorough history, including asking about any relationships between eating and syncope or lightheadedness, is important in the diagnosis of the disorder.

\section{References}

1. Spens T. Medical commentary 7:463, 1793. In: Major RH, ed. Classical Descriptions of Disease. $2^{\text {nd }}$ ed. Springfield, IL: Charles C. Thomas; 1939. 358.

2. Omi W, Murata Y, Yaegashi T, Inomata J, Fujioka M, Muramoto S. Swallow syncope, a case report and review of the literature. Cardiology 2006;105:75-79.

3. Patsilinakos SP, Antonatos DG, Spanodimos S, Nikolaou NI, Sotirellos K, Korkonikitas PI, Tsingas D. Swallow syncope in a patient with esophageal stenosis caused by an ascending aorta aneurysm: differential diagnosis from postprandial hypotension: a case report. Angiology 2007;58:126-129.

4. Kang KH, Cho WH, Kim MC, Chang HJ, Chung JI, Won DJ. Cases of swallow syncope induced by the activation of mechanorecepters in the lower esophagus. Korean J Intern Med 2005;20:68-71.

5. Carey BJ, de Caestecker J, Panerai RB. More on deglutition syncope. N Engl J Med 1999;341:1316-1377.

6. Gordon J, Saleem SM, Ngaage DL, Thorpe JA. Swallow syncope associated with paroxysmal atrial fibrillation. Eur J Cardiothorac Surg 2002;21:587-590.

7. Farb A, Valenti SA. Swallow syncope. Md Med J 1999; 48:151-154.

8. Marshall TM, Mizgala HF, Yeung-Lai-Wah JA, Steinbrecher UP. Successful treatment of deglutition syncope with oral betaadrenergic blockade. Can J Cardiol 1993;9:865-868.

9. Turan I, Ersoz G, Bor S. Swallow-induced syncope in a patient with achalasia. Dysphagia 2005;20:238-240.

10. Gawrieh S, Carroll T, Hogan WJ, Soergel KH, Shaker R. Swallow syncope in association with Schatzki ring and hypertensive esophageal peristalsis: report of three cases and review of the literature. Dysphagia 2005;20:273-277. 
11. Favaretto E, Schenal N, Russo N, Buja G, Iliceto S, Bilato C. An uncommon case of right-sided throat pain and swallow syncope. J Cardiovasc Med (Hagerstown) 2008;9:1152-1155.

12. Karamitsos TD, Arnold JR, Rider OJ, Francis JM, Ferrett C, Neubauer S, Becher H. Massive hiatus hernia impeding transoesophageal echocardiography in a patient with swallow-syncope syndrome. Hellenic J Cardiol 2009; 50:216-217.

13. Bajwa S, Stewart JA, Treadwell S, Lakhani DR. Swallow syncope: reflex or reflux? Postgrad Med J 2008;84:160-162.

14. Leitman M, Zyssman I, Abuhatzera S, Vasserman M, Ben Baruch C, Vered Z. A 37-year-old man with recurrent fainting: a short communication. Eur J Echocardiogr 2010;11:E30.

15. Casella F, Diana A, Bulgheroni M, Solbiati M, Ceriani E, Pentimalli F, Sagone A, Montano N. When water hurts. Pacing Clin Electrophysiol 2009;32:e25-e27.

16. Lee GY, Chang BS, Song JU, Ok CS, Sohn SY, Jo HC, Noh HJ, Choi SH, Kim JH, Kim JS. Deglutition syncope associated with ventricular asystole in a patient with permanent atrial fibrillation. Korean Circ J 2010;40:99-101.

17. Endean ED, Cavatassi W, Hansler J, Sorial E. Deglutition syncope: a manifestation of vagal hyperactivity following carotid endarterectomy. J Vasc Surg 2010;52:720-722.

18. Tuzcu V, Halakatti R. Swallow syncope associated with complete atrioventricular block in an adolescent. Pediatr Cardiol 2007;28:409-411.

19. Fahrner A, Rennhofer A, Kalmann N, Roggla G. Swallow syncope. Eur J Emerg Med 2008;15:122-123.

20. Boos CJ, Martin U, Cherry RC, Marshall HJ. Dangerous sandwiches. Lancet 2008;372:2164.

21. Woodruff J, Prudente L. Update on implantable pacemakers. J Cardiovasc Nurs 2005;20:261-268.

22. Armstrong P, McMillan D, and Simon J. Swallow syncope. Can Med Assoc J 1985;132:1281-1284.

23. Oishi Y, Ishimoto T, Nagase N, Mori K, Fujimoto S, Hayashi S, Ochi Y, Kobayashi K, Tabata T, Oki T. Syncope upon swallowing caused by an esophageal hiatal hernia compressing the left atrium: a case report. Echocardiography 2004;21:61-64.

24. Maekawa T, Suematsu M, Shimada T, Go M, Shimada T. Unusual swallow syncope caused by huge hiatal hernia. Intern Med 2002;41:199-201.

\section{Author Affiliations}

Subhashis Mitra, MD*; Tiffany Ludka, MD';

Shereif H. Rezkalla, MD*; Param P. Sharma, MD*;

Jiangming Luo, MD, PhDs

*Department of Internal Medicine, Marshfield Clinic, Marshfield, Wisconsin, USA

tDepartment of Medicine-Pediatrics, Marshfield Clinic, Marshfield, Wisconsin, USA

*Department of Cardiology, Marshfield Clinic,

Marshfield, Wisconsin, USA

§Department of Hospital Medicine,

Marshfield Clinic, Marshfield, Wisconsin, USA 